\title{
Enhanced Disinfection Effect of a Compound Disinfectant against Bovine Herpes Virus Type 1 at Low Temperature
}

\author{
Makoto Nagai $^{1,2}$, Ryoji Kamimura ${ }^{3}$, Reiji Seki ${ }^{3}$, Toshiaki Shimoyama ${ }^{1}$, \\ Takumi Kubota ${ }^{3}$, Junsuke Shirai ${ }^{1,2^{*}}$ \\ ${ }^{1}$ Department of Veterinary Medicine Faculty and Agriculture, Tokyo University of Agriculture and Technology, Tokyo, Japan \\ ${ }^{2}$ Research and Education Center for Prevention of Global Infectious Diseases of Animal, Tokyo, Japan \\ ${ }^{3}$ Tamura Pharmaceutical Co., Ltd., Tokyo, Japan \\ Email: ${ }^{*}$ jshirai@cc.tuat.ac.jp
}

Received July 5, 2013; revised August 5, 2013; accepted August 15, 2013

Copyright (C) 2013 Makoto Nagai et al. This is an open access article distributed under the Creative Commons Attribution License, which permits unrestricted use, distribution, and reproduction in any medium, provided the original work is properly cited.

\begin{abstract}
A compound disinfectant, which consisted of didecyldimethylammonium chloride (DDAC), ortho-dichlorobenzene (1,2-dichlorobenzene, ODB), and chlorocresol (4-chloro-3-methylphenol, CC), and its component chemicals were individually tested for effectiveness against bovine herpes virus type 1 (BHV-1). DDAC, DDAC+ODB, DDAC+CC, and $\mathrm{DDAC}+\mathrm{ODB}+\mathrm{CC}$ showed effectiveness against BHV-1 at room temperature. However, ODB, CC, and ODB $+\mathrm{CC}$ showed no virucidal effects. The effects of all disinfectants tested were decreased at low temperature. DDAC showed disinfectant effects at a dilution of $1 / 800$ and DDAC $+\mathrm{ODB}, \mathrm{DDAC}+\mathrm{CC}$, and DDAC $+\mathrm{ODB}+\mathrm{CC}$ at dilutions of 1/800 and $1 / 1600$ at low temperature in the presence of $2 \%$ fetal bovine serum (FBS) but ODB, CC, and ODB $+\mathrm{CC}$ showed no virucidal effects. At low temperature and in the presence of $10 \%$ FBS, DDAC, DDAC+ODB, and DDAC + CC showed disinfectant effects at dilutions of $1 / 800$, whereas $\mathrm{ODB}, \mathrm{CC}$, and $\mathrm{ODB}+\mathrm{CC}$ showed no virucidal effects. DDAC + ODB $+C C$ was more effective (at $1 / 800$ and 1/1600) than the other disinfectants under these conditions. In conclusion, a combination of three disinfectant components (DDAC+ODB $+\mathrm{CC}$ ), enhanced the disinfectant effects at low temperature and in organic matter contamination.
\end{abstract}

Keywords: Bovine Herpes Virus Type 1; Compound Disinfectant; Enhancing Disinfection; Low Temperature; Organic Matter Contamination

\section{Introduction}

Disinfection is the primary method that prevents the spread of infectious diseases. Not all disinfectants are effective against all pathogens; therefore, it is important to select an appropriate disinfectant [1-3]. Quaternary ammonium compounds (QACs) are used extensively for the disinfection of animal housing environments because they have low toxicity and are non-corrosive to metals $[1,2,4$, 5]. The QACs have lipophilic properties and affect lipidenveloped viruses $[3,6]$. Phenolic compounds are the oldest established active disinfectant substances and still play a major role in today's arsenal of disinfectants $[2,3]$. These compounds induce membrane damage and have a wide spectrum of activity against bacteria, enveloped viruses, fungi, and mycobacteria $[2,4]$. The ambient or surface temperature during the application of disinfectants is

${ }^{*}$ Corresponding author. important, and the effects of disinfectants are reduced at low temperature [7]. Some major diseases, including highly pathogenic avian influenza, winter diarrhea, and respiratory diseases of piglets and calves, such as infectious bovine rhinotracheitis, mainly break out in winter. The effectiveness of disinfectants is also decreased with organic matter contamination [1]. Therefore, it is critical when choosing a disinfectant to consider its effects under low temperature and contamination with organic matter. In the present study, we investigate whether a compound disinfectant is more effective than its component chemicals against bovine herpes virus type 1 (BHV-1), which causes respiratory disease in bovines during winter.

\section{Materials and Methods}

\subsection{Disinfectants}

We used the following disinfectants: $12 \%$ didecyldime- 
thylammonium chloride (DDAC), 70\% ortho-dichlorobenzene (1,2-dichlorobenzene, ODB), and 5\% chlorocresol (4-chloro-3-methylphenol, CC). Each was individually tested and $\mathrm{DDAC}+\mathrm{ODB}, \mathrm{DDAC}+\mathrm{CC}, \mathrm{ODB}+\mathrm{CC}$, and $\mathrm{DDAC}+\mathrm{ODB}+\mathrm{CC}$ were mixed and tested.

\subsection{Virus and Cell Culture}

BHV-1 was propagated on Madin-Darby bovine kidney (MDBK) cells. The cells were grown in Eagle's minimum essential medium (MEM) containing 5\% fetal bovine serum (FBS), 0.295\% tryptose phosphate broth (TPB), $0.292 \mathrm{mg} / \mathrm{mL}$ L-glutamine, $0.1 \%$ sodium bicarbonate, $200 \mathrm{U} / \mathrm{mL}$ penicillin, and $200 \mathrm{ug} / \mathrm{mL}$ streptomycin.

\subsection{Plaque Formation Assays}

Plaque formation assays were used to determine the viral titers before and after treatment with the disinfectants as described previously [8]. Briefly, viruses were inoculated onto MDBK cell monolayers grown for 1 or 2 days in 30-mm-diameter 6-well tissue culture plates and allowed to adsorb the tested viral materials for $1 \mathrm{~h}$ at $37^{\circ} \mathrm{C}$. The monolayers were then overlaid with $2 \mathrm{~mL}$ of MEM containing $0.295 \%$ TPB and $0.8 \%$ Bacto agar, and incubated for 3 days at $37^{\circ} \mathrm{C}$ in $5 \% \mathrm{CO}_{2}$. Monolayers were fixed and stained with a solution containing $10 \%$ methanol, $3 \%$ formalin, and $0.15 \%$ crystal violet. The titers were expressed as log plaque-forming unit (PFU) per $0.1 \mathrm{~mL}$.

\subsection{Evaluation of the Effect of Disinfectants on BHV-1}

BHV-1 suspensions containing $2 \%$ or $10 \%$ FBS were mixed with equal volumes of the disinfectants diluted to $1 / 800,1 / 1600,1 / 3200$, and $1 / 6400$ with distilled water. The mixtures were incubated at room temperature $\left(20^{\circ} \mathrm{C}\right)$ or on ice for $10 \mathrm{~min}$. Following incubation, the specimens were immediately diluted by MEM containing $10 \%$ FBS and titrated. Adequate virucidal effects for disinfection were considered to be at viral titer reductions of $\geq$ $3 \log 10$. The experiment at low temperature was repeated three times.

\section{Results}

\subsection{Effects of Disinfectants against BHV-1 at Room Temperature $\left(20^{\circ} \mathrm{C}\right)$}

The results of the efficacy evaluation of individual and mixed disinfectants at room temperature (about $20^{\circ} \mathrm{C}$ ) are shown in Figures 1 and 2. DDAC and DDAC $+\mathrm{ODB}+\mathrm{CC}$

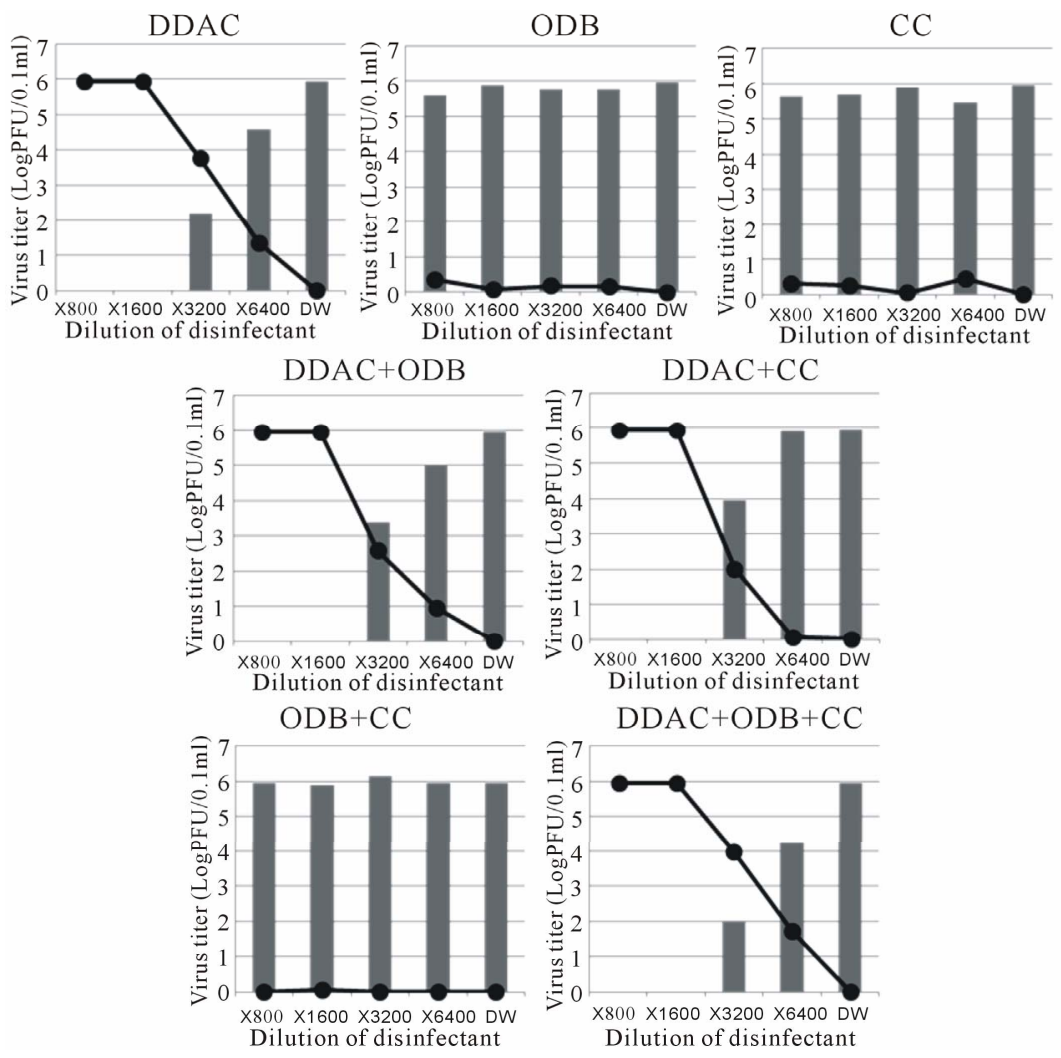

Figure 1. Disinfectant effects against viruses under low-concentration organic matter contamination at moderate temperature. The effects of DDAC, ODB, CC, DDAC+ODB, DDAC+CC, ODB+CC, and DDAC+ODB+CC against BHV-1 at room temperature (about $20^{\circ} \mathrm{C}$ ) containing $2 \%$ FBS. Lines show the titers of the inactivated virus and the bars indicate the titers of residual viruses. 

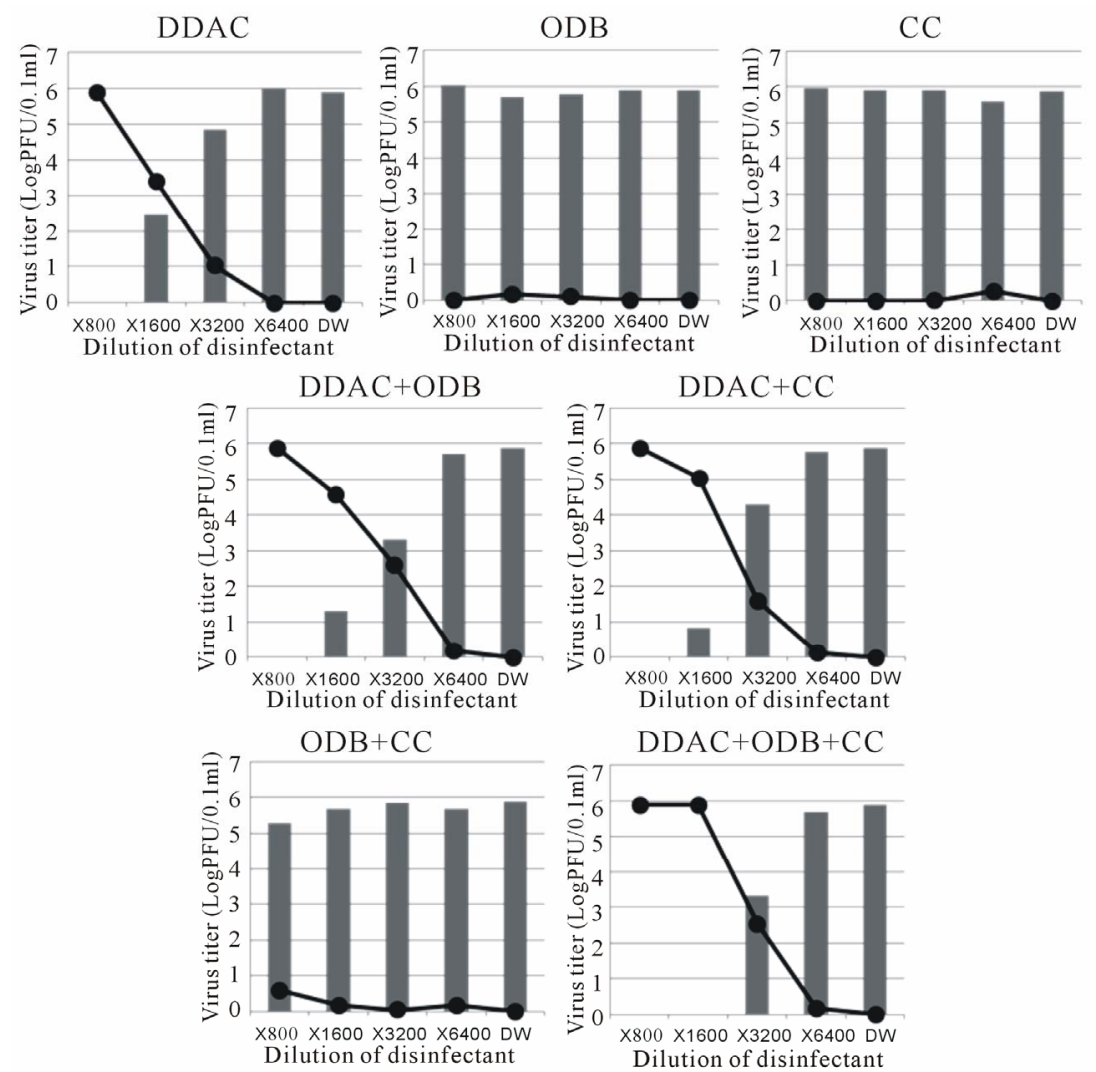

Figure 2. Disinfectant effects against viruses under high-concentration organic matter contamination moderate temperature. The effects of DDAC, ODB, CC, DDAC+ODB, DDAC+CC, ODB+CC, and DDAC+ODB+CC against BHV-1 at room temperature (about $20^{\circ} \mathrm{C}$ ) containing $10 \%$ FBS. Lines show the titers of inactivated viruses and the bars indicate those of residual viruses.

were found to have adequate disinfectant effects at dilutions of $1 / 800$ to $1 / 3200$, and DDAC+ODB and DDAC+ $\mathrm{CC}$ at dilutions of $1 / 800$ and $1 / 1600$ in the presence of $2 \%$ FBS. In the presence of $10 \%$ FBS, the effects of $\mathrm{DDAC}, \mathrm{DDAC}+\mathrm{ODB}, \mathrm{DDAC}+\mathrm{CC}$, and $\mathrm{DDAC}+\mathrm{ODB}+$ $\mathrm{CC}$ were adequate at dilutions of $1 / 800$ and $1 / 1600$. However, ODB, CC and ODB $+\mathrm{CC}$ showed no disinfectant effects in either experiment.

\subsection{Effects of Disinfectants against BHV-1 at Low Temperature}

The results of the efficacy evaluation of individual and mixed disinfectants at low temperature (about $4^{\circ} \mathrm{C}$ ) are shown in Figures 3 and 4. The disinfectant effects of DDAC were adequate at dilution of $1 / 800$, while those of $\mathrm{DDAC}+\mathrm{ODB}, \mathrm{DDAC}+\mathrm{CC}$, and $\mathrm{DDAC}+\mathrm{ODB}+\mathrm{CC}$ were adequate at dilutions of $1 / 800$ to $1 / 1600$ in the presence of $2 \%$ FBS. DDAC, DDAC $+\mathrm{ODB}$, and DDAC $+\mathrm{CC}$ showed adequate efficiency at a concentration of $1 / 800$ in the presence of $10 \% \mathrm{FBS}$, whereas the effects of $\mathrm{DDAC}+\mathrm{ODB}+\mathrm{CC}$ were adequate at dilutions of $1 / 800$ and $1 / 1600$. ODB, CC, and ODB $+\mathrm{CC}$ showed no disinfectant effects in either experiment.

\section{Discussion}

BHV-1 is a major pathogen that causes respiratory diseases in cattle during the winter and had 237 recognized outbreaks in Japan from 2004 to 2011. Therefore, we choose BHV-1 as a viral indicator of disinfectant effects. Trikil (Tamura Pharmaceutical Co., Ltd., Tokyo, Japan), which consists of DDAC, ODB, and CC, is developed to have a wide spectrum of activity against bacteria, viruses, fungi, and oocysts of coccidia. Trikil is effective against avian influenza virus at low temperature $[9,10]$. However, there are no comparative reports on the efficacy of compound disinfectants and their component chemicals at low temperature or when contaminated by high concentrations of organic matter. Therefore, we investigate the comparative efficacy of a compound disinfectant and its components against BHV-1.

In this study, we confirmed that the tested compound disinfectant $(\mathrm{DDAC}+\mathrm{ODB}+\mathrm{CC})$ was more effective than its components against BHV-1 at low temperature in high concentrations of organic matter. DDAC showed an adequate effect at room temperature. However, the effect of DDAC decreased remarkably at low temperature. DDAC is a kind of QAC: it induces disintegration and 

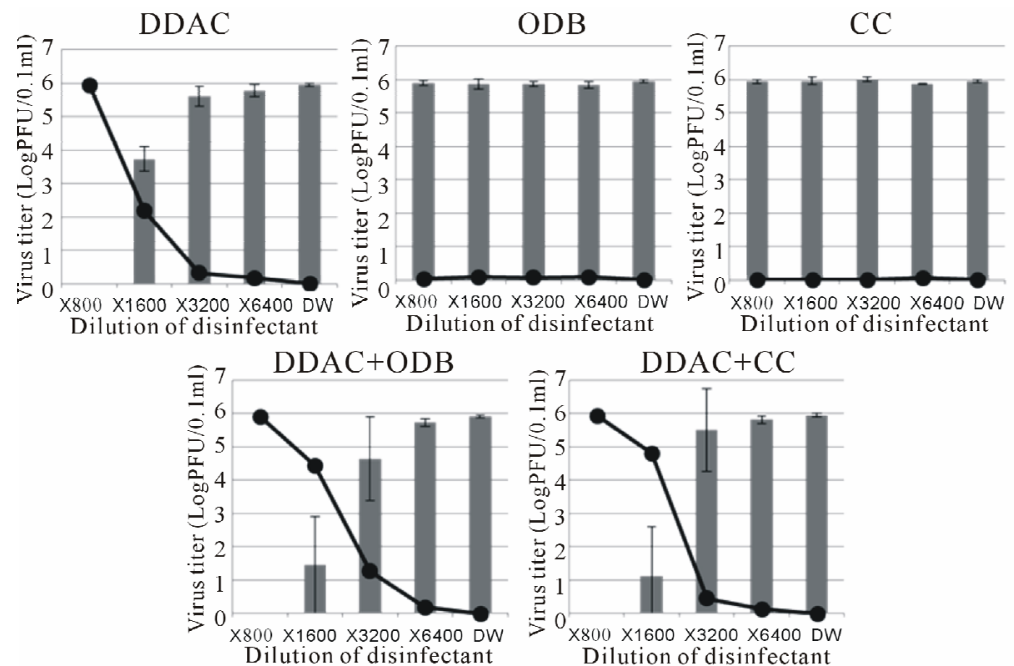

$\mathrm{ODB}+\mathrm{CC}$
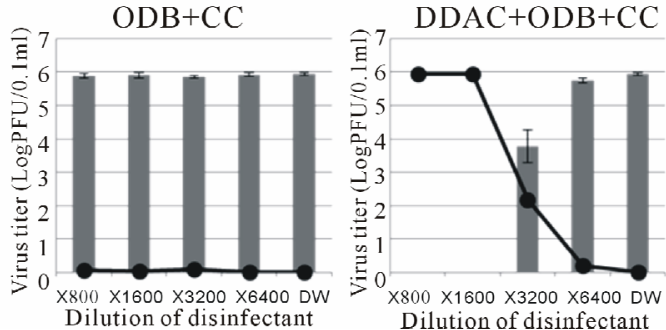

Figure 3. Disinfectant effects against viruses under low-concentration organic matter contamination at low temperature. The effects of DDAC, ODB, CC, DDAC+ODB, DDAC+CC, ODB+CC, and DDAC+ODB+CC against BHV-1 on ice (about $\left.4^{\circ} \mathrm{C}\right)$ containing $2 \%$ FBS. Lines show titers of inactivated viruses and bars indicate those of residual viruses.

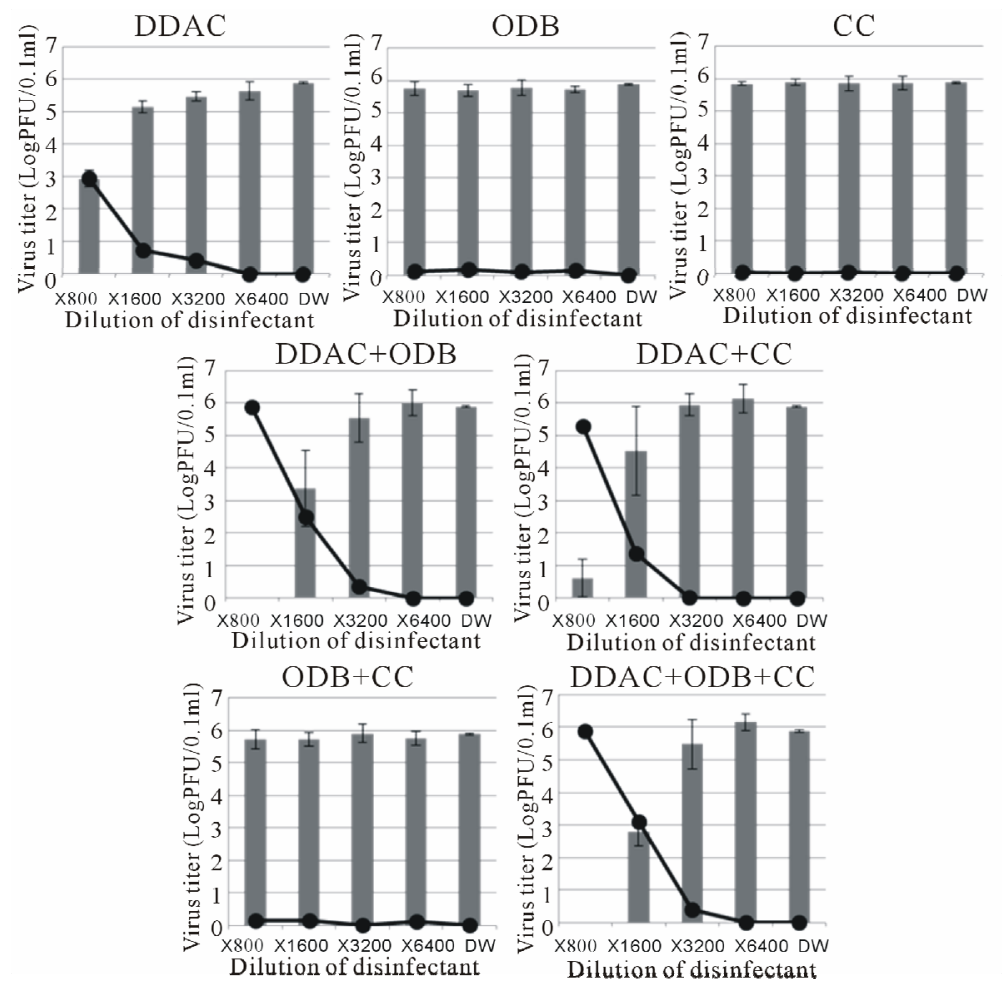

Figure 4. Disinfectant effects against viruses under high-concentration organic matter contamination at low temperature. The effects of DDAC, ODB, CC, DDAC+ODB, DDAC+CC, ODB+CC, and DDAC+ODB+CC against BHV-1 on ice (about $\left.4^{\circ} \mathrm{C}\right)$ containing $10 \%$ FBS. Lines show titers of inactivated viruses and bars indicate titers of residual viruses. 
morphological changes of enveloped viruses, resulting in loss of infectivity [5]. It seems that a reduction in the molecular motions of DDAC at low temperature influences its virucidal effects. Nevertheless, ODB and CC had no virucidal effects against BHV-1, and DDAC+ $\mathrm{ODB}+\mathrm{CC}$ showed the greatest effects. The penetration of disinfectants into viruses and their interactions with viral components has not been extensively studied. However, QACs are known to generally increase effectiveness in slightly alkaline conditions. Alkaline conditions help QACs penetrate viral particles, leaving them fragile and partially destroyed, as well as easy to penetrate $[8,11,12]$. ODB and $\mathrm{CC}$ are phenolic compounds and they might enhance the virucidal effects of DDAC by some unknown mechanism, similar to the effect of alkalines on viruses. Elucidation of the exact mechanism of action of a disinfectant against viruses is a complicated process [6]. Further studies are required to reveal the virucidal mechanisms. Our experiments are conducted in the presence of organic matter, which is known to be a main factor influencing the efficacy of disinfectants. The highest level of effectiveness seen in the compound disinfectants $(\mathrm{DDAC}+\mathrm{ODB}+\mathrm{CC})$ in $10 \% \mathrm{FBS}$ is believed to be due to the retained activity of phenolics in the presence of organic matter [1].

Kassaify et al. [13] reported that the use of QACs in combination with phenols enhanced the virucidal effects, which could be due to degradation of the capsid by phenols. Although the kinds of disinfectants used in their study were different from those in our study, the use of mixed compatible compounds for disinfection is an effective method. We conclude that a compound consisting of the three disinfectants tested enhances disinfectant effects at low temperature under high levels of organic matter contamination, and is a useful disinfectant to prevent the spread of pathogens prevalent in winter.

\section{REFERENCES}

[1] A. G. Grow, "Writing Guidelines to Require Disinfection," Revue Scientifique et Technique, Vol. 14, No. 2, 1995, pp. 469-477.
[2] D. J. Jefferey, "Chemicals Used as Disinfectants: Active Ingredients and Enhancing Additives," Revue Scientifique et Technique, Vol. 14, No. 1, 1995, pp. 57-74.

[3] J. Shirai, "Disinfection against the Outbreaks of Foot and Mouth Disease (FMD)," Journal of Disaster Research, Vol. 7, No. 3, 2012, pp. 264-273.

[4] G. Bruins and J. A. Dyer, "Environmental Considerations of Disinfectants Used in Agriculture," Revue Scientifique et Technique, Vol. 14, No. 2, 1995, pp. 81-94.

[5] G. McDonnell and A. D. Russell, "Antiseptics and Disinfectants: Activity, Action, and Resistance," Clinical Microbiology Reviews, Vol. 12, No. 1, 1999, pp. 147-179.

[6] P. Maris, "Modes of Action of Disinfectants," Revue Scientifique et Technique, Vol. 14, No. 1, 1995, pp. 47-55.

[7] R. F. Kahrs, "General Disinfection Guidelines," Revue Scientifique et Technique, Vol. 14, No. 1, 1995, pp. 105122.

[8] J. Shirai, T. Kanno, T. Inoue, S. Mitsubayashi and R. Seki, "Effects of Quaternary Ammonium Compounds with $0.1 \%$ Sodium Hydroxide on Swine Vesicular Disease Virus," The Journal of Veterinary Medical Science, Vol. 59, No. 5, 1997, pp. 323-328. doi:10.1292/jvms.59.323

[9] Y. Sakoda, R. Seki and H. Kida, "Effects of Disinfectants against Avian Influenza Virus," The Japanese Journal of Animal Hygiene, Vol. 32, No. 2, 2006, pp. 67-70 (in Japanese).

[10] Y. Sakoda, Y. Yoshimi, S. Kurokawa and H. Kida, "Effects of Disinfectants against Avian Influenza Viruses," Journal of the Japan Veterinary Medical Association, Vol. 60, No. 7, 2007, pp. 519-522 (in Japanese).

[11] J. Shirai, T. Kanno, Y. Tsuchiya, S. Mitsubayashi and R. Seki, "Effects of Chlorine, Iodine, and Quaternary Ammonium Compound Disinfectants on Several Exotic Disease viruses," The Journal of Veterinary Medical Science, Vol. 62, No. 1, 2000, pp. 85-92. doi:10.1292/jvms.62.85

[12] J. Shirai, R. Seki, R. Kamimura and S. Mitsubayashi, "Effects of Invert Soap with 0.05\% Sodium Hydroxide on Infectious Bursal Disease Virus," Avian Disease, Vol. 38, No. 2, 1994, pp. 240-243. doi:10.2307/1591943

[13] Z. G. Kassaify, R. G. E. Hakim, E. G. Rayya, H. A. Shaib and E. K. Barbour, "Preliminary Study on the Efficacy and Safety of Eight Individual and Blended Disinfectants against Poultry and Dairy Indicator Organisms," Veteriaria Italiana, Vol. 43, No. 4, 2007, pp. 821-830. 